\title{
Vaccination Status and Clinical Spectrum of Children with Pyogenic Meningitis in A Tertiary Care Hospital of Hazara Division, Pakistan
}

\section{Bibi Aalia ${ }^{1}$, Syed Sajid Hussain Shah ${ }^{2}$}

${ }^{1}$ Assistant Professor, Department of Pediatrics, Lady Reading Hospital Peshawar, Khyber Pakhtunkhwa, Pakistan ${ }^{2}$ Assistant Professor, Department of Pediatrics Nephrology, Institute of kidney diseases, Khyber Pakhtunkhwa, Pakistan

\section{ABSTRACT}

Background: Pyogenic meningitis is one of the serious causes of mortality and morbidity in children. It is more prevalent in third world countries with poor vaccination coverage. This study was done to determine the vaccination status and clinical spectrum of pyogenic meningitis in children presenting to a tertiary care hospital.

Methods: This cross-sectional study was carried out from August, 2017 till January, 2020 over 2.5 years. Records of children who got admitted in pediatric B ward, of either gender between ages of 1 month to 14 years diagnosed as case of pyogenic meningitis were included. Records of vaccination status along with signs of meningeal irritation, complications and outcome during hospital stay were documented. Data was analyzed by SPSS 20 and chi square test applied. P value $<0.05$ was taken as significant.

Results: There were 117 patients, 78 males and 39 females. Age ranged from 1 month to 14 years with mean age of $5.51 \pm 4.19$ years. Patients who were vaccinated up to date were $49.6 \%$ and $37.6 \%$ were not vaccinated at all. Main presenting feature was fever and seizures especially under one year of age. There was significant association between seizures and age group with $\mathrm{p}$ value of 0.001 . Signs of meningeal irritation (neck stiffness, brudzinski sign, kerning sign) and paradoxical irritability were present in 85 (72.6\%) patients mostly above 1 year of age. There was significant association between signs of meningeal irritation and age group ( 5 years and above) with $p$ value of $<0.001 .110$ ( $94 \%$ ) got discharged and one (0.9\%) patient was referred while $6(5.1 \%)$ patients expired. There was significant association between stay duration and vaccination status. $(p=0.018)$

Conclusion: Fever was the most common presentation and vaccinated children with pyogenic meningitis had shorter stay in hospital.

Keywords: irritability, meningitis, paradoxical, seizures, vaccination

Authors' Contribution:

${ }^{1-2}$ Conception; Literature research; manuscript design and drafting; Critical analysis and manuscript review; Data analysis; Manuscript Editing.
Correspondence:

Syed Sajid Hussain Shah

Email: syed_sajid20@yahool.com

\section{Article info:}

Received: May 13, 2020

Accepted: August 30, 2021
Cite this article. Aalia B, Shah SSH. Vaccination Status and Clinical Spectrum of Children with Pyogenic Meningitis in A Tertiary Care Hospital of Hazara Division, Pakistan. J Islamabad Med Dental Coll. 2021; 10(3): 145-151. Doi: 10.35787/jimdc.v10i3.553
Funding Source: Nil Conflict of Interest: Ni

\section{Introduction}

Pyogenic or bacterial meningitis is inflammation of meninges of spinal cord and brain. It is still one of the major causes of mortality and morbidity in children all over the world. ${ }^{1}$ Worldwide there are almost 135000 deaths due to bacterial meningitis every year. ${ }^{2}$ Streptococcus pneumonia is one of the leading pathogens in children causing the meningitis along with Neisseria meningitides. Haemophilus influenzae type $b$ is also one of the major pathogens in infants and early childhood. ${ }^{3}$ Streptococcus 
pneumonia and Haemophilus influenzae type $b$ (Hib) are responsible for the most of the bacterial meningitis sequelae in children. ${ }^{4,5}$

After introduction of pneumococcal conjugate vaccines including PCV-10 and PCV-13, reduction in rates of pneumococcal infections was expected globally. ${ }^{6}$ In Pakistan, extended program on immunization (EPI) was started in 1978 and it included vaccination against Haemophilus influenza. In 2012 vaccine against streptococcus pneumonia was also included in EPI schedule. ${ }^{7,8}$ Though due to coverage of vaccination, there is decrease in incidence of pyogenic meningitis yet it is prevalent in the country. One of surveillance studies done in southern Pakistan showed that majority of pyogenic meningitis in children is caused by Streptococcus pneumonia and $\mathrm{Hib} .{ }^{9}$ Another study done in Lahore showed that pneumonia followed by meningitis are the leading infectious diseases especially in rural areas. ${ }^{10}$ The frequency of pyogenic meningitis was $7.6 \%$ in children presenting with fever with fits in one of the hospitals of Islamabad, Pakistan. ${ }^{11}$

The number of patients presenting and admitting with diagnosis of pyogenic meningitis has increased over the last few years. This study was conducted to determine the vaccination status and clinical spectrum of pyogenic meningitis in our setup that may help the health care professionals and public health administrators in identifying the magnitude of the problem and allocation of resources, giving emphasis on vaccination and educating masses.

\section{Material and Methods}

This cross-sectional study was conducted in paediatric B ward of Ayub Teaching Hospital, Abbottabad. The data was collected retrospectively after taking approval from institutional review board. Sample size was calculated by open epi sample size calculator taking frequency of pyogenic meningitis as $7.6 \% .^{11}$ The calculated sample size was 108 patients. Data was retrieved from patient files from August, 2017 till January, 2020. Records of children of either gender between ages of 1 month to 14 years were included who were diagnosed as case of pyogenic meningitis on clinical basis, cerebrospinal fluid (CSF) findings along with CT scan. The CSF finding suggestive of bacterial meningitis was increase in cell count and presence of neutrophils. Records of patients with diagnosis of tuberculous meningitis, meningoencephalitis/encephalitis, febrile seizures and seizure disorders were excluded. Records of vaccination status were considered as up to date vaccinated, if vaccine schedule was complete according to EPI vaccine card. If any dose was found to be missed, according to age, it was taken as partially vaccinated and if none of vaccine given apart from polio drops then taken as not vaccinated. All patients initially suspected or diagnosed with pyogenic meningitis were started on intravenous antibiotics including ceftriaxone and vancomycin. Due to non-availability of CSF cultures, antibiotics covering gram negative and gram-positive bacteria were given. Dexamethasone was also given as antiinflammatory for 72 to 96 hours. Retrieved from data, presenting features included, fever, signs of meningeal irritation including neck stiffness, brudzinski sign, kerning sign, paradoxical irritability in children less than 1.5 years of age. Development of complications during hospital stay secondary to meningitis were documented on specific proforma. Data was analyzed using SPSS version 20. Vaccination status, clinical spectrum of the disease, duration of hospital stays and patient's outcome was analyzed and chi square test applied as test of significance. $P$ value 0.05 was considered as statistically significant.

\section{Results}

In this study total of 117 patients were included. Out of 117 patients, $78(66.7 \%)$ were males and 39 (33.3\%) were females. Age of patients ranged from 1 month to 14 years. Their baseline details have been given in (table I). Total $82(70.1 \%)$ patients 
stayed in hospital for up to 7 days. Stay of remaining 35 (29.9\%) patients was 8 days or more. Majority $(58.1 \%)$ of patients of pyogenic meningitis were less than five years of age. The main presenting feature of patients was fever present in 86 (73.5\%) patients while 31 (26.5\%) patients were not having history of fever. Association of fever with gender and age category did not reveal any significant relation ( $P$ value 0.8 and 0.1 respectively). Another presenting feature was seizure; which was present in 46 (39.3\%) patients. Out of 46 patients, 36 (78.3\%) patients were having generalized tonic clonic seizures and 10 (21.7\%) patients were having focal seizures. There was significant association between seizures and age group. Majority of patients having seizures were under one year of age. Association of seizures with gender was also significant. Larger number of patients having seizures were males. Association of seizures with fever was also significant. Majority of patients presenting with seizures also had fever (Table II). At time of presentation, signs of meningeal irritation (neck stiffness, brudzinski sign, kerning sign) and paradoxical irritability were present in 85 (72.6\%) patients. There was significant association between signs of meningeal irritation and age group. Majority of patients presenting with seizures were above 5 years of age. Association of meningeal irritation with gender was non-significant (Table III).
Out of 117 patients, 58 (49.6\%) were vaccinated up to date, $15(12.8 \%)$ were partially vaccinated while $44(37.6 \%)$ were not vaccinated at all apart from taking polio drops. Male children who were not vaccinated were $35.89 \%$ while female nonvaccinated children were $41 \%$. Fever, seizures and signs of meningeal irritation were not having significant relationship with vaccination status $(p$ value $>0.5$ ). Association of vaccination status with patients stay in hospital was significant. Children who were vaccinated up to date had stay duration of up to 7 days while unvaccinated children had more duration of stay in hospital (Table IV).

Out of 117 patients, 110 (94\%) got discharged and one $(0.9 \%)$ patient was referred while $6(5.1 \%)$ patients expired. Majority (88.9\%) were not having any complication at time of discharge from hospital. The most common complication observed in hospital was hydrocephalus which was present in 7 (6\%) patients followed by Hemiplegia in 5 (4.2\%) patients. Dural sinus thrombosis was present in one (0.9\%) patient.

There was also significant association between seizures as presenting feature and CT scan findings with $p$ value of 0.033 . Association of duration of stay in hospital and outcome, complications or age category was non-significant.

\begin{tabular}{|c|c|c|c|c|}
\hline \multicolumn{7}{|c|}{ Table I: Baseline data of patients in study (n=117). } \\
\hline & Minimum & Maximum & Mean & Std. Deviation \\
\hline Stay duration (days) & 1 & 16 & 6.75 & 2.796 \\
\hline Age (years) & 0.10 & 13.00 & 5.1517 & 4.19448 \\
\hline CSF cell count (cells/ul) & 2 & 28000 & 3550.44 & 4841.232 \\
\hline Polymorphs (percent) & 0 & 95 & 64.85 & 30.390 \\
\hline Lymphocytes (percent) & 5 & 100 & 35.38 & 30.516 \\
\hline CSF sugar (mg/dl) & 1 & 157 & 47.11 & 29.075 \\
\hline CSF protein (mg/dl) & 5 & 649 & 125.32 & 106.891 \\
\hline
\end{tabular}

\begin{tabular}{|c|c|c|c|}
\hline \multicolumn{5}{|c|}{ Table II: Association of seizures with age, gender and fever ( $\mathbf{n = 1 1 7})$} \\
\hline \multirow{2}{*}{ Variables } & Seizures & $\begin{array}{c}\text { Total } \\
\mathrm{n}(\%)\end{array}$ & P value \\
\cline { 2 - 4 } & $\begin{array}{c}\text { No } \\
\mathrm{n}(\%)\end{array}$ & & \\
\hline
\end{tabular}




\begin{tabular}{|c|c|c|c|c|}
\hline Age (Years) & & & & \\
\hline Up to 1 & 20 (17.09) & $12(10.26)$ & $32(27.35)$ & \multirow[t]{3}{*}{0.001} \\
\hline $1-5$ & $16(13.68)$ & $20(17.09)$ & $36(30.77)$ & \\
\hline More than 5 & $10(8.55)$ & $39(33.33)$ & $49(41.88)$ & \\
\hline \multicolumn{5}{|l|}{ Gender } \\
\hline Male & $36(30.77)$ & $42(35.90)$ & 78 (66.67) & \multirow[t]{2}{*}{0.032} \\
\hline Female & $10(8.55)$ & 29 (24.79) & 39 (33.33) & \\
\hline \multicolumn{5}{|l|}{ Fever } \\
\hline Yes & 39 (33.33) & 47 (40.17) & $86(73.50)$ & 0.026 \\
\hline No & $7(5.98)$ & $24(20.51)$ & 31 (26.49) & \\
\hline Total & $46(39.32)$ & 71 (60.69) & $117(100)$ & \\
\hline
\end{tabular}

\begin{tabular}{|c|c|c|c|c|}
\hline \multicolumn{5}{|c|}{ Table III: Association of signs of meningeal irritation with age and gender $(n=117)$} \\
\hline \multirow[t]{2}{*}{ Gender } & \multicolumn{2}{|c|}{ Signs of meningeal irritation } & \multirow{2}{*}{$\begin{array}{l}\text { Total } \\
\text { n (\%) }\end{array}$} & \multirow[t]{2}{*}{$P$ value } \\
\hline & $\begin{array}{l}\text { Yes } \\
\text { n (\%) }\end{array}$ & $\begin{array}{c}\text { No } \\
\mathrm{n}(\%)\end{array}$ & & \\
\hline \multicolumn{5}{|l|}{ Age (Years) } \\
\hline Up to 1 & $15(12.82)$ & $17(14.53)$ & $32(27.35)$ & \multirow[t]{3}{*}{0.001} \\
\hline $1-5$ & $27(23.08)$ & $9(7.69)$ & $36(30.77)$ & \\
\hline More than 5 & $43(36.75)$ & $6(5.13)$ & $49(41.88)$ & \\
\hline \multicolumn{5}{|l|}{ Gender } \\
\hline Male & $57(48.72)$ & $21(17.95)$ & 78 (66.67) & \multirow{3}{*}{0.883} \\
\hline Female & $28(23.93)$ & $11(9.40)$ & $39(33.33)$ & \\
\hline Total & $85(72.65)$ & $32(27.35)$ & $117(100)$ & \\
\hline
\end{tabular}

\begin{tabular}{|c|c|c|c|c|c|}
\hline \multirow{3}{*}{$\begin{array}{l}\text { Duration of stay } \\
\text { (days) }\end{array}$} & \multirow{2}{*}{\multicolumn{3}{|c|}{ Vaccination status }} & \multirow{3}{*}{$\begin{array}{l}\text { Total } \\
\mathrm{n}(\%)\end{array}$} & \multirow{3}{*}{$\begin{array}{c}\mathrm{P} \\
\text { valu } \\
\mathrm{e}\end{array}$} \\
\hline & & & & & \\
\hline & $\begin{array}{l}\text { Up to date } \\
\text { n (\%) }\end{array}$ & $\begin{array}{c}\text { Partially vaccinated } \\
\text { n (\%) }\end{array}$ & $\begin{array}{c}\text { Not vaccinated } \\
\mathrm{n}(\%) \\
\end{array}$ & & \\
\hline Up to 7 & $40(34.19)$ & $15(12.82)$ & $27(23.08)$ & $82(70.08)$ & \\
\hline 8 or more & $18(15.38)$ & $0(0)$ & $17(14.53)$ & $35(29.91)$ & \\
\hline Total & $58(49.57)$ & $15(12.82)$ & $44(37.61)$ & $117(100)$ & $\begin{array}{c}0.01 \\
8\end{array}$ \\
\hline
\end{tabular}

\section{Discussion}

Though the incidence of bacterial meningitis has decreased with inclusion of new vaccines and expansion of immunization program especially in third world countries yet the morbidity and mortality associated with it is quite high. Therefore, timely diagnosis of bacterial meningitis is one of the most important aspects in management including status epilepticus and prevention of the sequelae. ${ }^{8}$ The presenting features of bacterial meningitis are fever, neck stiffness, seizures and altered consciousness level. Children appear sicker and in infants, the main presenting features are poor feeding, lethargy, seizures and paradoxical irritability. ${ }^{12,13}$ Studies have shown that fluid management may be associated with decrease in neurological sequelae in children. ${ }^{14}$

Hadi $\mathrm{N}$ et al15 did one study in Iran and in their study positive CSF cultures were more in children less than five years of age in $57.1 \%$ patients while inn our 
study about $60 \%$ of patients were aged less than five years.Sallam AKA16 study done in Yemen showed that the age group which presented with meningitis was between 4 months and 3 years. Bari $A$ et al 17 studied the clinical spectrum in children 1 month to 5 years of age with bacterial meningitis at Children hospital, Lahore. Their male to female ratio was 1.7:1 in comparison to our study ratio of 2:1. Majority of patients (68.3\%) in Bari A et al study was less than one year of age while in our study $27.4 \%$ children were less than one year of age. Fayyaz $\mathrm{J}$ et al18 published one study about CT scan in children presenting with acute bacterial meningitis. Their study male to female ratio was 2.3:1 while in our study it was 2:1.

Fayyaz $\mathrm{J}$ et $\mathrm{al}^{19}$ did study in Aga Khan University hospital and studied the presenting features of children with acute bacterial meningitis. Their study included 192 patients. In their study the main presenting feature was fever in $86 \%$ of patients while in our study fever as presenting feature was present in $73.5 \%$ patients. We included the paradoxical irritability as signs of meningeal irritation, $72.6 \%$ patients in our study had signs of meningeal irritation at presentation, while in Fayyaz $J$ et al study, $78.56 \%$ patients had signs of meningeal irritation. Their findings also included that the signs of meningeal irritation were more elicitable in children who were more than five years of age like in our study. Complications were noted in 3.12\% patients in contrast to our study in which complications were noted in $11.1 \%$ patients. lio $\mathrm{K}$ et $\mathrm{al}^{20}$ in one case report emphasized that absence of neck stiffness cannot rule out meningitis in infants, physical appearance and fever also matters. In our study $27.2 \%$ patients had no sign of meningeal irritation at time of presentation. In one of the studies by Amin $\mathrm{M}$ et $\mathrm{al}^{21}$ done in Bhawal Victoria Hospital, $63.2 \%$ children presented with history of seizures while in our study $39.3 \%$ children had history of seizures at presentation.

In Fayyaz J et al ${ }^{18}$ study, CT scan was done in $59.4 \%$ of patients and it was reported normal in $78.94 \%$ patients. While in our study CT scan was done in $40.2 \%$ of patients.

In Bari A et al $^{17}$ study, $45.2 \%$ children were vaccinated up to date, as in our study where $49.6 \%$ children were vaccinated up to date. Bari $A$ et al study was done in Lahore and patients presenting to children hospital were from rural areas. In our hospital also the majority of children presenting with meningitis are from rural areas that may be the reason for majority of children not being vaccinated. In Amin $\mathrm{M}$ et al ${ }^{17}$ study, only $50.5 \%$ children with meningitis were vaccinated up to date and $22.7 \%$ were not vaccinated at all while in our study $45.2 \%$ children were vaccinated up to date and $37.6 \%$ children were not vaccinated at all. In their study, $63.2 \%$ children presented with history of seizures while in our study $39.3 \%$ children had history of seizures at presentation. Though they did CSF culture yet in their study $24.1 \%$ patients had Neisseria meningitides. In our study $12 \%$ with meningococcemia were having meningitis. Truong J et $\mathrm{al}^{22}$ studied the impact of incorrect vaccination in France leading to meningitis in children. They reported 48 cases which were due to vaccine preventable bacteria. On the top of list was Neisseria meningitides which was in $54.2 \%$ cases. In our study only $45.2 \%$ were vaccinated up to date and $12 \%$ cases were with meningococcal meningitis.

Andriatahirintsoa EJPR et $\mathrm{al}^{23}$ in their study observed for the impact of pneumococcal conjugated vaccine (PCV)10 in children and concluded that incidence of meningitis caused by pneumococcal bacteria was reduced after introduction of vaccine in immunization program. In Pakistan, PCV was introduced in EPI program in October 2012. In our study $37.6 \%$ children were not vaccinated at all and $12.8 \%$ children were only partially vaccinated. Shrestha RG et $\mathrm{al}^{24}$ did one study in one of the hospitals of Nepal and the objective was doing CSF culture in children with meningitis. Their study showed that $72.2 \%$ meningitis was caused by Haemophilus influenzae. In Pakistan, EPI program 
includes Haemophilus influenzae vaccine. We did not do any CSF culture due to various reasons.

In Sallam AKA ${ }^{16}$ study; mortality was $14.28 \%$ in children with pyogenic meningitis. In comparison mortality was $5.13 \%$ in our study, which is quite less as compared to Sallam AKA study. In a study done by Fayyaz $\mathrm{J}$ et $\mathrm{a}^{18}$ the mortality was $3.1 \%$.

There are limitations in this study as the data was collected retrospectively. Also, we only documented the outcome in hospital. Patients follow up is required for the possible long term neurological sequelae.

\section{Conclusion}

Fever was most common presentation in patients of pyogenic meningitis. Seizures were common in infants reporting with meningitis, whereas signs of meningeal irritation were mostly absent in them. Male gender was more likely to have seizures. Vaccinated children had shorter stay in hospital.

\section{Recommendations}

Infants less than one year presenting with paradoxical irritability and history of seizures, should be worked up for possible meningitis. Multicenter studies are required to further confirm the findings. Also, there are significant numbers of children who are not vaccinated at all or not up to date. Public awareness on vaccination should be the priority.

\section{References}

1. Qureshi MAA, Jesrani A, Magsi K, Nayab S. Diagnostic Accuracy of Post Contrast Magnetic Resonance Imaging for Meningitis Taking Lumbar Puncture as Gold Standard. Experience at Nishtar HospitalMultan. TIJMCCS 2020;1(1):1-4. Doi: 10.46718/JBGSR.2020.06.000150

2. McNeil HC, Jefferies JMC, Clarke SC. Vaccine preventable meningitis in Malaysia: epidemiology and management. Expert Rev Anti Infect Ther 2015; 13:705-14. Doi: 10.1586/14787210.2015.1033401

3. Oordt-Speets AM, Bolijn R, Van Hoorn RC, BhavsarA, Kyaw $\mathrm{MH}$. Global etiology of bacterial meningitis: $\mathrm{A}$ systematic review and meta-analysis. PloS One
2018;13:

e0198772.

Doi:10.1371/journal.pone.0198772

4. Alamarat Z, Hasbun R. Management of Acute Bacterial Meningitis in Children. Infection and Drug Resistance 2020; 13:4077-89. Doi: 10.2147/IDR.S240162.

5. McIntyre PB, O’Brien KL, Greenwood B, Beek DVD. Effect of vaccines on bacterial meningitis worldwide. Lancet 2012; 380:1703-11. Doi: 10.1016/S01406736(12)61187-8.

6. Fatima T, Malik F, Khan E, Mir F, Shakoor S. Clinical features and outcomes of pneumococcal bacteremia among children at a tertiary care hospital. Biomed Biotechnol Res J 2018; 2:152-5. Doi: 10.4103/bbrj.bbrj_15_18

7. Masud T, Navaratne KV. The expanded program on immunization in Pakistan. Recommendations for improving performance. Health, nutrition and population (HNP) discussion paper. The World Bank. 2012.

8. Chetan C, Sharma S, Mathur SB, Jain P, Aneja S. Clinical Profile and Short-term Outcome of Pediatric Status Epilepticus at a Tertiary-care Center in Northern India. Indian Pediatrics. 2020; 57:213-17. PMID: 32198859

9. Zaidi AK, Khan H, Lasi R, Mahesar W, Sindh Meningitis Group. Surveillance of pneumococcal meningitis among children in Sindh, southern Pakistan. Clinical Infectious Diseases. 2009 ;48(Supplement_2): S12935. Doi: 10.1086/596491

10. Rashid $M$, Iqbal Bano $A H$. Prevalence of Common Infectious Diseases in Paediatric Age Group Admitted in Children's Hospital Lahore, Pakistan. Int J Front Sci. 2017;1(1):19-28. Doi:10.37978/tijfs.v1i1.12

11. Siddiqui HB, Haider N, Khan Z. Frequency of acute bacterial meningitis in children with first episode of febrile seizures. J Pak Med Assoc. 2017;67(7):1054-8. PMID: 28770886

12. Abiy H, Shiferaw Z, Tafere Y. Clinical Outcome of Meningitis and Its Risk Factors Among Children Admitted in Debre Markos Referral Hospital Pediatric Ward, Northwest Ethiopia,2019. Research Square; 2020. Doi: 10.21203/rs.3.rs-36044/v1.

13. Kumar A, Shankar M, Chaudhary AK. Etiological Profile of Children Admitted with Seizures in A Tertiary Care Hospital. IOSR-JDMS 2020;19(2):6-8. Doi: 10.9790/0853-1902120608

14. Maconochie IK, Bhaumik S. Fluid therapy for acute bacterial meningitis. Cochrane Database Syst Rev 2016;(11): CD004786. Doi: 10.1002/14651858.CD004786.pub5.

15. Hadi N, Bagheri K. A five-year retrospective multicenter study on etiology and antibiotic resistance pattern of bacterial meningitis among 
Iranian children. IEM. 2019;5(4):17-24. ISSN:2588-4115.

16. Sallam AKA. Etiology and presentation of acute bacterial meningitis in children at Al-Thawrah Hospital, Sana`a, Yemen. J Ayub Med Coll 2004;16(4):40-3. PMID: 15762062

17. Bari A, Zeeshan F, Zafar A, Ejaz H, Iftikhar A, Rathore AW. Childhood Acute Bacterial Meningitis: Clinical Spectrum, Bacteriological Profile and Outcome. J Coll Physicians Surg Pak 2016;26(10):822-6. PMID: 27806810

18. Fayyaz J, Khursheed M, Zia N, Feroze A, Khan UR, Rehman $A$, et al .CT scan in children with acute bacterial meningitis: Experience from Emergency Department of a tertiary-care hospital in Karachi, Pakistan. J Pak Med Assoc 2014;64(4):419-22. PMID: 24864636

19. Fayyaz J, Khursheed M, Zia N, Feroze A, Rehman A, Hamid A. Age related clinical manifestation of acute bacterial meningitis in children presenting to emergency department of a tertiary care hospital. J Pak Med Assoc 2014;64(3):296-9. PMID: 24864603
20. lio K, Ogawa Y, Ihara T, Horikoshi Y, Hataya H. Nuchal Rigidity in Infantile Bacterial Meningitis. J Pediatr 2019; 207:255. Doi: 10.1016/j.jpeds.2018.10.008.

21. Amin M, Khurshid A, Ahmad M, Javed Z. Etiology and outcome of culture proven bacterial meningitis in children 6 to 24 months of age. Professional Med J 2019;26(09):1451-6.

Doi: 10.29309/TPMJ/2019.26.09.2562

22. Truong J, Levy C, Prot-Labarthe S, Nguyen HPK, Grimpre E, Faye A, et al. Vaccine-preventable meningitis in French children with incorrect vaccination status from 2011 to 2013 . Archives de Pe' diatrie 2020; 27:1-5. Doi: 10.1016/j.arcped.2019.10.008.

23. Andriatahirintsoa EJPR, Raboba JL, Rahajamanana VL, Rakotozanany AL, Nimpa MM, Masembe YV, et al. Impact of 10-Valent Pneumococcal Conjugate Vaccine on Bacterial Meningitis in Madagascar. Clin Infect Dis 2019;69(S2): S121-5. Doi: 10.1093/cid/ciz504.

24. Shrestha RG, Tandukar S, Ansari S, Subedi A, Shrestha $A$, Poudel $R$, et al. Bacterial meningitis in children under 15 years of age in Nepal. BMC Pediatrics 2015; 15:94. Doi: 10.1186/s12887-015-0416-6. 